\title{
Identification of tower-wake distortions using sonic anemometer and lidar measurements
}

\author{
Katherine McCaffrey ${ }^{1,2}$, Paul T. Quelet ${ }^{3}$, Aditya Choukulkar $^{1,4}$, James M. Wilczak $^{2}$, Daniel E. Wolfe ${ }^{2}$, \\ Steven P. Oncley ${ }^{5}$, W. Alan Brewer ${ }^{4}$, Mithu Debnath ${ }^{6}$, Ryan Ashton ${ }^{6}$, G. Valerio Iungo ${ }^{6}$, and Julie K. Lundquist ${ }^{3,7}$ \\ ${ }^{1}$ Cooperative Institute for Research in Environmental Sciences, University of Colorado at Boulder, Boulder, Colorado, USA \\ ${ }^{2}$ National Oceanic and Atmospheric Administration, Earth Systems Research Laboratory Physical Sciences Division, \\ Boulder, Colorado, USA \\ ${ }^{3}$ Department of Atmospheric and Oceanic Sciences, University of Colorado at Boulder, Boulder, Colorado, USA \\ ${ }^{4}$ National Oceanic and Atmospheric Administration, Earth Systems Research Laboratory Chemical Sciences Division, \\ Boulder, Colorado, USA \\ ${ }^{5}$ National Center for Atmospheric Research, Boulder, Colorado, USA \\ ${ }^{6}$ Department of Mechanical Engineering, University of Texas at Dallas, Dallas, Texas, USA \\ ${ }^{7}$ National Renewable Energy Laboratory, Golden, Colorado, USA
}

Correspondence to: Katherine McCaffrey (katherine.mccaffrey@noaa.gov)

Received: 23 May 2016 - Published in Atmos. Meas. Tech. Discuss.: 22 July 2016

Revised: 30 December 2016 - Accepted: 3 January 2017 - Published: 2 February 2017

\begin{abstract}
The eXperimental Planetary boundary layer Instrumentation Assessment (XPIA) field campaign took place in March through May 2015 at the Boulder Atmospheric Observatory, utilizing its $300 \mathrm{~m}$ meteorological tower, instrumented with two sonic anemometers mounted on opposite sides of the tower at six heights. This allowed for at least one sonic anemometer at each level to be upstream of the tower at all times and for identification of the times when a sonic anemometer is in the wake of the tower frame. Other instrumentation, including profiling and scanning lidars aided in the identification of the tower wake. Here we compare pairs of sonic anemometers at the same heights to identify the range of directions that are affected by the tower for each of the opposing booms. The mean velocity and turbulent kinetic energy are used to quantify the wake impact on these first- and second-order wind measurements, showing up to a $50 \%$ reduction in wind speed and an order of magnitude increase in turbulent kinetic energy. Comparisons of wind speeds from profiling and scanning lidars confirmed the extent of the tower wake, with the same reduction in wind speed observed in the tower wake, and a speed-up effect around the wake boundaries. Wind direction differences between pairs of sonic anemometers and between sonic anemometers and lidars can also be significant, as the flow is deflected by the
\end{abstract}

tower structure. Comparisons of lengths of averaging intervals showed a decrease in wind speed deficit with longer averages, but the flow deflection remains constant over longer averages. Furthermore, asymmetry exists in the tower effects due to the geometry and placement of the booms on the triangular tower. An analysis of the percentage of observations in the wake that must be removed from 2 min mean wind speed and 20 min turbulent values showed that removing even small portions of the time interval due to wakes impacts these two quantities. However, a vast majority of intervals have no observations in the tower wake, so removing the full 2 or $20 \mathrm{~min}$ intervals does not diminish the XPIA dataset.

\section{Introduction}

Sonic anemometry is a pivotal tool for measuring highfrequency motions and fluxes in the atmosphere, and tall towers are commonly used to mount these instruments in order to observe the surface layer of the atmosphere. However, the tower structure can disrupt the flow, introducing biases and inaccuracies in the wind speed, direction, and turbulence measurements. The sonic anemometers commonly mounted on the $300 \mathrm{~m}$ meteorological tower at the Boulder 


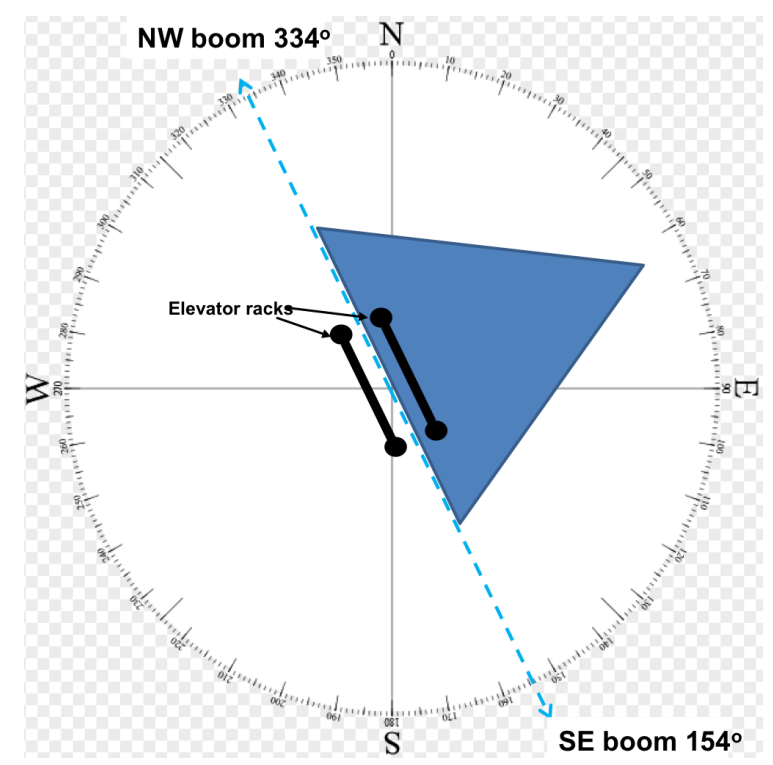

Figure 1. Plan view schematic of the BAO tower as the blue equilateral triangle, with the northwest and southeast booms depicted and their orientations relative to north. The interior elevator track and exterior carriage track are also shown on the southwest face.

Atmospheric Observatory (BAO) in Erie, Colorado, are a rare resource for observing the planetary boundary layer (PBL) as well as mesoscale phenomena. The BAO tower has booms at six heights on two sides, extending to the northwest and southeast, which are capable of holding diverse meteorological sensors. However, the structure of the tower (Hall, 1976; Kaimal and Gaynor, 1983) disrupts the free-stream ambient flow experienced by the downstream sensors. Therefore, the tower frame wakes the northwest boom during southeasterly winds, and, conversely, the tower frame wakes the southeast boom during northwesterly winds (Fig. 1). The aim of this study is to use sonic anemometry and lidar technology to precisely define the wake region around the BAO tower, where the meteorological measurements are impacted by the presence of the tower. The wake regions, compared to freestream measurements, are characterized by lower observed wind speeds, as well as increased turbulent motions. Furthermore, biases in wind direction are also observed when comparing sonic anemometers and wind lidar observations. Quantifying free-stream wind speed reduction magnitudes provides guidance on instrument measurement uncertainties.

Previous studies of tower wakes have found a 35-40\% reduction in wind speeds due to towers of different geometries (Dabberdt, 1968; Cermak and Horn, 1968), and computational fluid dynamics approaches have supported those observations (Orlando et al., 2011; Fabre et al., 2014). Lira et al. (2016) compiled the possible uncertainties in estimates of wind energy production, including a discussion of uncertainty due to assembly of the wind sensors. Citing the International Energy Agency (IEA, 1999), for a triangular lattice tower with a constant inflow, 2-D Navier-Stokes computations and actuator disc theory resulted in more than a $0.5 \%$ average deficit in velocity present out to a distance of 5.7 times the width of the tower face. However, these studies are limited in their applicability to different tower geometries as well as the possible atmospheric conditions in the boundary layer. Each meteorological tower possesses unique geometry and boom layout, so similar analyses must be completed for each tower under scrutiny. Analysis of sonic anemometer observations on the $200 \mathrm{~m}$ tower at the SWiFT site in Texas identified the wake of the tower frame in the increase in turbulence intensity at the sonic anemometers mounted on booms on a single side of the tower (Kelley and Ennis, 2016). At the Høvsøre site in Denmark, the meteorological tower has cup anemometers and wind vanes on the south booms and sonic anemometers on the north booms, but Peña et al. (2016) state that tower distortions are generally neglected in meteorological studies, since the westerly and easterly winds are predominant and more homogenous. The current study stands uniquely as a comprehensive method of determining any meteorological tower wake, using either a set of in situ anemometers in and out of the wake or independent wind measurements (e.g., profiling lidars). This thorough analysis for the BAO tower eliminates, hereafter, the need to repeatedly quantify the angles of the tower wake for each subsequent measurement campaign or deployment of sonic anemometry on the BAO tower. The paper is organized as follows: Sect. 2 will introduce the field campaign and observational datasets, Sect. 3 will identify wake effects using pairs of sonic anemometers, Sect. 4 will utilize two lidar datasets for wake identification, Sect. 5 will use both sonic anemometer and lidar data to describe the flow deflection around the BAO tower, Sect. 6 will discuss the impacts of varying levels of tower-wake contamination, and Sect. 7 will conclude.

\section{XPIA field campaign}

From 2 March to 31 May 2015, the US Department of Energy funded the eXperimental Planetary boundary layer Instrumentation Assessment (XPIA) to assess the ability of several remote sensing instruments for observing the PBL (Lundquist et al., 2016a, b). A key aspect of this campaign was measuring the PBL with in situ instrumentation, and the BAO's $300 \mathrm{~m}$ tower was heavily instrumented for this purpose. All data are publicly available in the Data Archive and Portal, found at https://a2e.energy.gov/projects/xpia.

\subsection{BAO $300 \mathrm{~m}$ tower}

The BAO is maintained by the Physical Sciences Division of the Earth System's Research Laboratory at the National Oceanic and Atmospheric Administration (NOAA-ESRL PSD) in Boulder, Colorado (Kaimal and Gaynor, 1983). The 


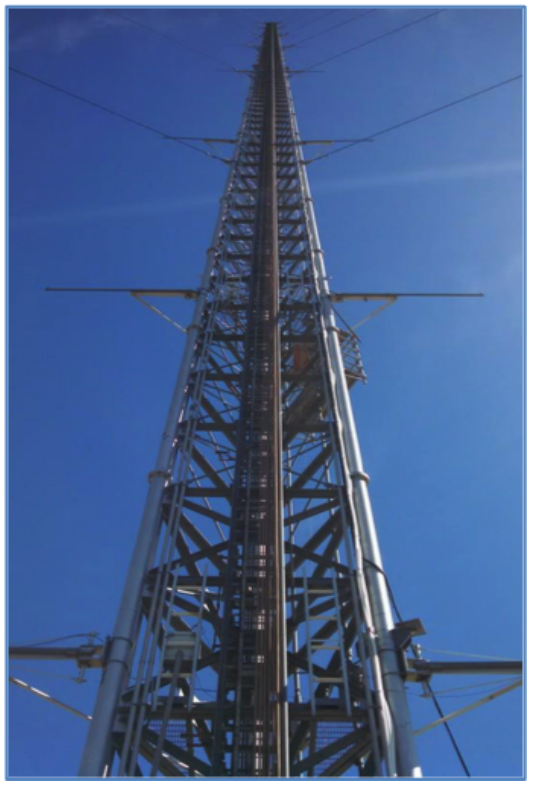

Figure 2. Photograph of the BAO tower, looking up at the southwest face. The northwest booms are pictured extended to the left, with the southeast booms to the right. The elevator and carriage tracks are pictured in the center of the southwest face.

BAO is located about $30 \mathrm{~km}$ north of Denver, $\mathrm{CO}$, and $25 \mathrm{~km}$ east of the foothills of the Rocky Mountains, with relatively flat terrain (see Lundquist et al., 2016a, for a detailed terrain description). The centerpiece of the site is the $300 \mathrm{~m}$ meteorological tower and permanently operating instrumentation including a ceilometer and mono-static sodar, as well as surface flux stations. Several field campaigns have also included scanning and profiling radars, lidars, sodars, microwave radiometers, and other surface, radiation, and chemical sensors (Kaimal et al., 1986; Stone et al., 2011; Brown et al., 2013, and many others).

The BAO tower is an equilateral, triangular, open-lattice structure, $3 \mathrm{~m}$ on each side, with two booms extending from the southwest-facing side (see Fig. 1) at six heights every $50 \mathrm{~m}$ from 50 to $300 \mathrm{~m}$. At each height, the northwest boom is oriented at $334^{\circ}$ from north, and the southeast boom points at $154^{\circ}$. All booms are $4.3 \mathrm{~m}$ long, from the center of the sonic anemometer to the tower leg, with the exception of the $250 \mathrm{~m}$ southeast boom, which is $3.3 \mathrm{~m}$ long. Though the structure of the tower is open lattice, electrical and other equipment is present at the heights of each boom, introducing further flow blockage. ${ }^{1}$ The southwest face of the tower also contains an elevator and accompanying track on the inside of the tower and a carriage lift on the outside (see Figs. 1 and 2).

\footnotetext{
${ }^{1}$ Though the $300 \mathrm{~m}$ booms are at the top of the tower and this level has more equipment inside the tower structure, and although the $250 \mathrm{~m}$ boom is shorter, the results at these levels showed statistically insignificant differences from the other heights and will thus not be compared independently.
}

During XPIA, the BAO tower was equipped with 12 Campbell Scientific CSAT3 sonic anemometers provided by the Characterizing the Atmospheric Boundary Layer (CABL) program of the National Center for Atmospheric Research and the University of Colorado, one mounted on each pair of booms at six heights of 50, 100, 150, 200, 250, and $300 \mathrm{~m}$ above ground level (a.g.l.), as well as temperature and humidity sensors at each height. The sonic anemometer data were sampled at $20 \mathrm{~Hz}$, and a quality-control scheme was repeated four times, each time removing the data outside 6 standard deviations $(6 \sigma)$ from the mean. In total, less than $0.1 \%$ of the data were removed by this procedure. The availability of observations on opposite sides of the tower allowed an extensive study of the tower wake, since one sonic anemometer will receive unobstructed flow when the other is in the wake. Prior to this experiment, the sonic anemometers were calibrated, with measurement resolution (maximum offset error) of $0.1 \mathrm{~cm} \mathrm{~s}^{-1}\left(8 \mathrm{~cm} \mathrm{~s}^{-1}\right)$ in the horizontal and $0.05 \mathrm{~cm} \mathrm{~s}^{-1}\left(4 \mathrm{~cm} \mathrm{~s}^{-1}\right)$ in the vertical.

\subsection{Profiling and scanning lidars}

During XPIA, the BAO was also the host to many wind lidars, including a Leosphere WINDCUBE ${ }^{\circledR}$ Offshore 8.66 profiling lidar (WCv2) and three Leosphere 200S scanning lidars. The WCv2 was located $130 \mathrm{~m}$ directly south of the BAO tower at the lidar "supersite". The WCv2 samples lineof-sight (LOS) velocities in four cardinal directions along a nominally $28^{\circ}$ azimuth from vertical, followed by a fifth, vertically pointed beam; each beam requires approximately 1 second. Range gates were centered on 40, 50, 60, 80, 100, $120,140,150,160$, and $180 \mathrm{~m}$ a.g.1, with $10-20 \mathrm{~m}$ pulse lengths. The $1 \mathrm{~s}$ wind speed estimates were averaged into 2 min estimates presented here.

The 200S scanning lidars performed several scan geometries to measure the 3-D wind field (Lundquist et al., 2016a). One of these scan geometries, called "virtual tower stares" (VTS; Calhoun et al., 2006), involved coordinated scanning by the three $200 \mathrm{~S}$ lidars to interrogate a common volume (Fig. 3a). Several configurations of the VTS techniques were tested during the 12-day period and were found to have very good agreement $(R=0.97$ and mean difference of $-0.03 \mathrm{~m} \mathrm{~s}^{-1}$ for wind speed, and $R=0.99$ and mean difference of $0.30^{\circ}$ for wind direction) with the sonic anemometer measurements (Lundquist et al., 2016a). In this paper, 3 days of VTS measurements from 21 to 24 March where the 200S scanning lidars performed coordinated $15 \mathrm{~min}$ stares at three sonic levels $(50,100$, and $150 \mathrm{~m})$ are used to assess the impact of tower structure wake on sonic anemometer measurements. For the duration of the VTS, the 200S scanning lidars operated with a $2 \mathrm{~Hz}$ data rate and $50 \mathrm{~m}$ pulse width. Within each of the $15 \mathrm{~min}$ stares, the $2 \mathrm{~Hz}$ co-located LOS measurements from the three lidars were accumulated into $2 \mathrm{~s}$ windows and least squares fitted to obtain the wind speed and direction. For this experiment, measurements are consid- 
ered co-located when the centers of the range gates from the three 200 S lidars fall within a $35 \mathrm{~m} \times 35 \mathrm{~m}$ box whose center is $10 \mathrm{~m}$ south of the SE sonic anemometers on the BAO tower (cyan box in Fig. 3b). A schematic of the VTS and its horizontal footprint compared to the BAO tower is shown in Fig. 3. The blue, brown, and red lines indicate the extent of the range gates from the three 200S lidars (Dalek1, Dalek2, and UTD, respectively) whose centers (defined by the small circles) fall within this common volume.

An estimate of the horizontal footprint of the VTS measurement is indicated by the black circle in Fig. 3b which encompasses the outermost extents of the three range gates used in the VTS fit and whose center is defined by the circumcenter of the outermost points. The diameter of this circle was found to be approximately $60 \mathrm{~m}$. The size of the horizontal footprint of the VTS, thus estimated, compared to the tower footprint indicates that the wind measurements performed by the VTS should be sufficiently insensitive to the tower-wake effects and hence can be used to investigate the effect of the tower wake on the sonic anemometer measurements. In addition, for this 3-day period, the average LOS uncertainty for the 200S scanning lidars was estimated to be $0.15 \mathrm{~m} \mathrm{~s}^{-1}$. With an average wind speed during this period of $4.17 \mathrm{~m} \mathrm{~s}^{-1}$, the uncertainty was $3.6 \%$ of the average wind speed and, therefore, any velocity differences greater than this presents a clearly detectable signal.

\section{Wake identification: sonic anemometer comparison}

As an example of the wake effects from the BAO tower, Fig. 4 demonstrates the deviation in wind speeds as the wind directions varies. Winds on 4 April 2015 changed direction and crossed the axis of the booms, creating wakes around each of the booms at different times. Before 03:00 UTC, the $2 \mathrm{~min}$ average wind speed (Fig. $4 \mathrm{a}$ ) observed by the sonic anemometers on the northwest boom and southeast booms is very similar. However, between 03:00 and 07:00 UTC, the speed measured by the northwest sonic anemometer decreases substantially, while the measurement from the southeast sonic anemometer remains relatively constant. During this interval, the winds (Fig. 4b) are coming from the southeast, nearly parallel to the southeast boom orientation, so that the BAO tower frame is waking the northwest sonic anemometer. When the wind direction is not near the orientation of either boom, the sonic anemometers measure nearly the same wind speeds (between 07:00 and 10:00 UTC). This exemplifies the data contamination from tower waking; a quality control scheme must remove data points when the winds blow from a range of directions impacted by the tower.

Two quantities - mean wind speed and turbulent kinetic energy (TKE) - are used to identify distortion of the freestream flow from the BAO tower wake when comparing the sonic anemometers on opposing booms. At all times, at least one of the two sonic anemometers will be experienc-
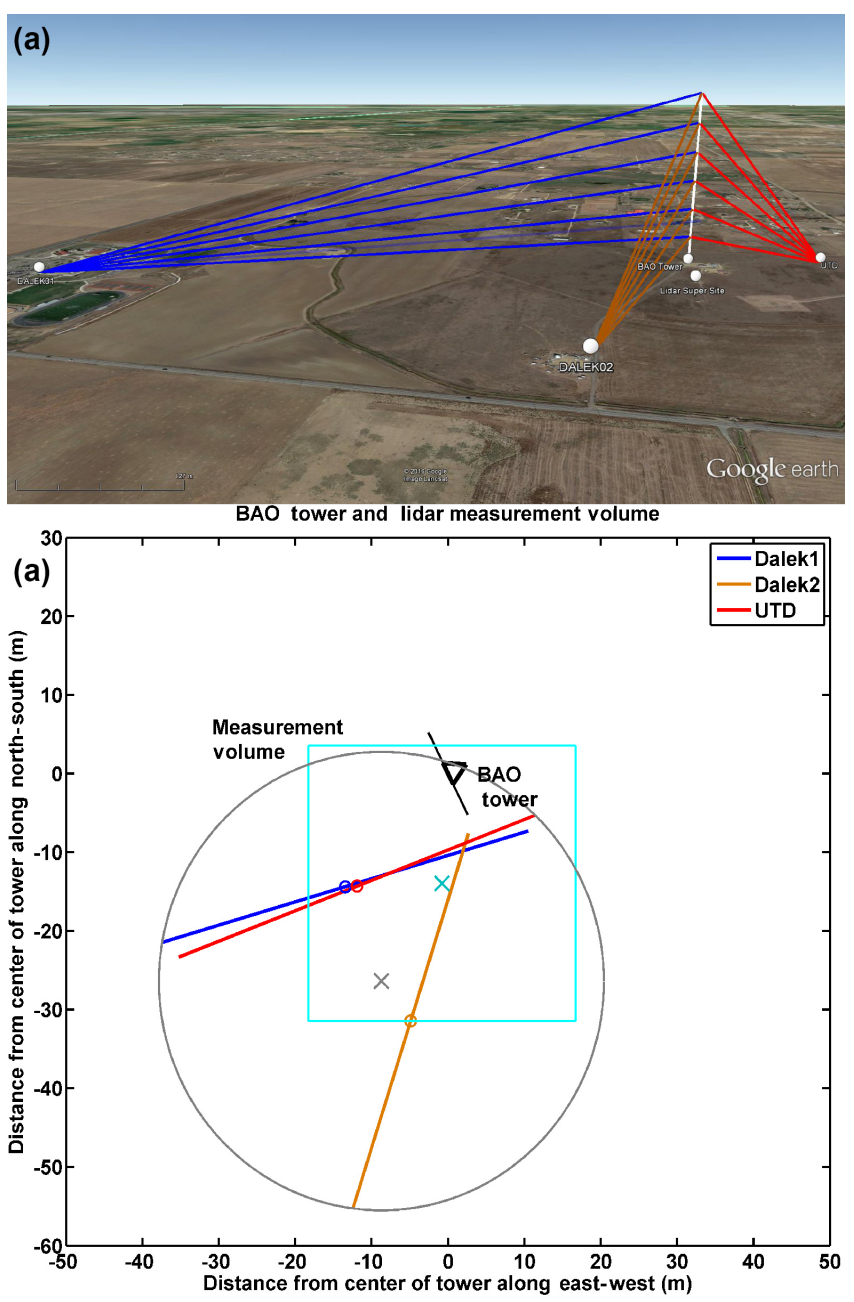

Figure 3. Top: schematic of the triple-Doppler virtual tower stares (VTS) of the three Leosphere 200S scanning lidars (Dalek1: blue, Dalek2: brown, and UTD: red), as they stare at the BAO tower's six levels of sonic anemometers at 50,100, 150, 200, 250, and $300 \mathrm{~m}$ a.g.1. The WCv2 is also shown near the BAO tower. Bottom: bird's-eye view of the measurement volume (cyan box, with $\mathrm{x}$ at the center) resulting from the range gates of the three scanning lidars, drawn with circles at the centers of the beams, to scale. The footprint of the beams of the VTS is shown in the black circle, with an $\mathrm{x}$ at the center.

ing undisturbed flow, providing a base measurement to diagnose the magnitude of the wake effect on the other sonic anemometer's observations. By comparing the mean speed and TKE observed by both sonic anemometers over the full range of possible wind directions, the free-stream flow distortion effects of the BAO tower can be determined.

\subsection{Mean speed}

When a sonic anemometer is in the wake of the BAO tower frame, it will measure slower wind speeds, as demonstrated in Fig. 4. To identify the angular swath at which a wake is 

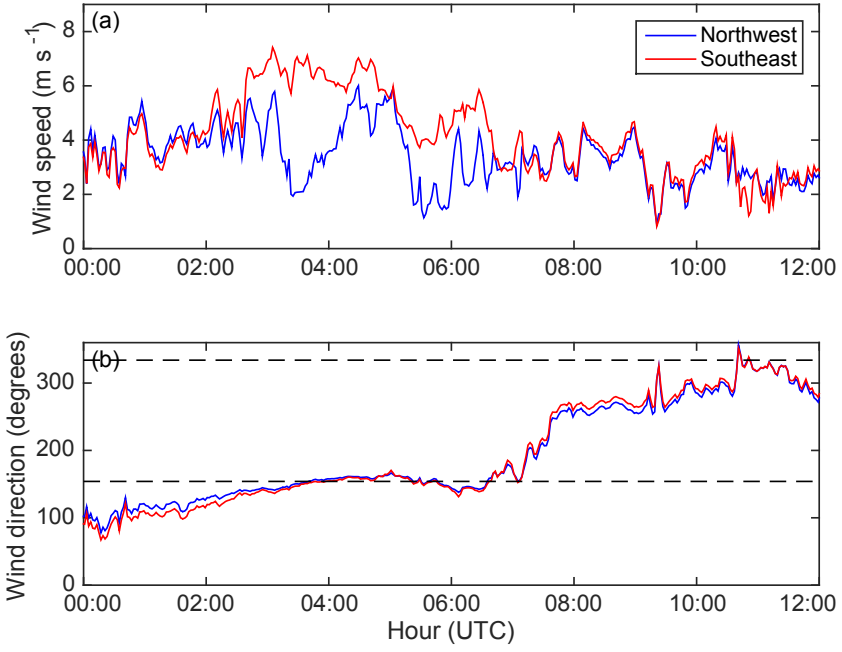

Figure 4. Two-minute average wind speed (a) and direction (b) from the $50 \mathrm{~m}$ sonic anemometers on the northwest boom (blue) and southeast boom (red), from 00:00 to 12:00 UTC on 4 April 2015. Dashed lines in (b) show the angles of the boom orientations at 154 and $334^{\circ}$ from north.

imposed on each sonic anemometer, the 2 min mean wind speed over the full 3-month period was compared between the sonic anemometer datasets. The comparison is shown in Fig. 5, as the ratio (southeast/northwest) of mean wind speeds as a function of direction, binned in $5^{\circ}$ intervals centered on $5,15^{\circ}$ etc. Deviations from 1 indicate the waking effect of the tower on the sonic anemometer measurements. To identify the wake on the northwest sonic anemometer, the wind direction from the southeast sonic anemometer was used (red line), showing that the northwest sonic anemometer measures lower wind speeds than the southeast for winds coming from between approximately 115 and $170^{\circ}$. The average speeds measured by the northwest sonic anemometers can be half that of the southeast sonic anemometer for directions where the tower-wake effect is at its maximum. To identify the wake on the southeast sonic anemometer, the wind direction from the northwest sonic anemometer was used (blue line), showing that the southeast sonic anemometer measures lower wind speeds than the northwest between 315 and $10^{\circ}$. Though the directions from the upstream sonic anemometer should be used to identify the wake in the downstream sonic anemometer, using the directions of the sonic anemometer in the wake produces the nearly same results (compare red and blue lines). Separating the sonic anemometer observations into daytime (unstable) and nighttime (stable) conditions (not pictured), we find only small differences: the peak wind speed ratio when the northwest booms were in the tower wake was $15 \%$ larger during the daytime than at night and $4 \%$ larger in the daytime when the southeast booms were in the wake. However, the directional extent of the tower wake does not vary with stability.

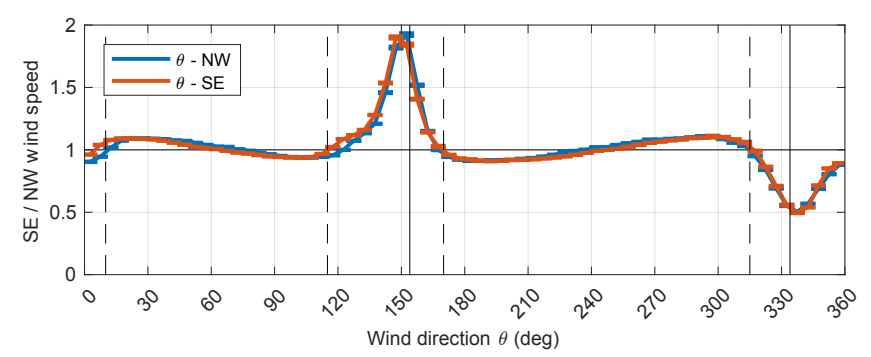

Figure 5. Ratio of 2 min mean wind speed from the southeast versus northwest sonic anemometers using data from all six heights for the full 3 months of measurements made during XPIA. The $5^{\circ}$ bins are determined by the northwest (blue) and southeast (red) sonic anemometers' wind directions. Solid vertical lines indicate the orientations of the booms at 154 and $334^{\circ}$ from north and dashed vertical lines indicate the boundaries of the wake, defined by the wind speed deficit, at $115-170$ and $315-10^{\circ}$. Error bars represent 1 standard deviation of the mean.

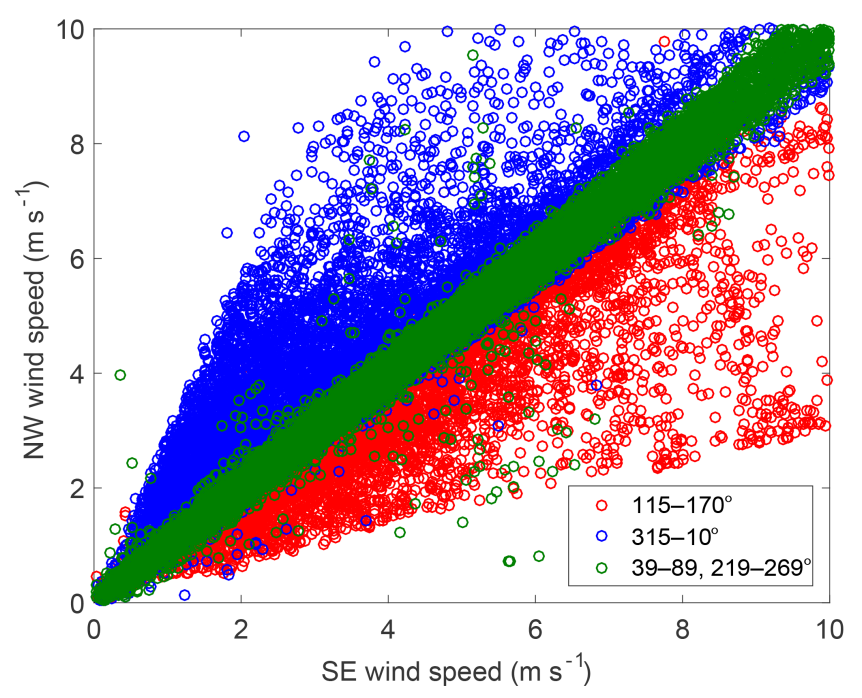

Figure 6. Two-minute mean wind speed from the northwest and southeast sonic anemometers at $50 \mathrm{~m}$, in three bins contained in the northwest sonic anemometer's wake $\left(115-170^{\circ}\right.$, red), the southeast sonic anemometer's wake $\left(315-10^{\circ}\right.$, blue), and non-wake regions (38-89 and 219-269 ${ }^{\circ}$, green).

Using the angular swaths found in Fig. 5, Fig. 6 shows the southeast versus northwest sonic anemometers' 2 min wind speed measurements, compared in three directional sectors. The chosen angular ranges correspond to the BAO towerwake regions that affect the sonic anemometers, as well as an undisturbed region. The magnitudes of the disagreement in the individual measurements that are in the tower wake (red and blue points) appropriately show a wind speed decrease due to the tower wake, while the sonic anemometer measurements are in close agreement when not in the wake (green points). The deficits on individual measurements are 
up to approximately two-thirds of the speeds measured by the sonic anemometer in the undisturbed flow.

Interestingly, an opposite effect is also observed in the ratio of mean wind speeds in Fig. 5 adjacent to the wake regions $\left(90-120,170-230,250-315\right.$, and $\left.10-50^{\circ}\right)$, where the ratio rises above or falls below 1 , but with a much lower amplitude. For these directions, the (nearly) downstream sonic anemometer measures a higher wind speed than the upstream instrument. This inverse-wake effect is, on average, approximately $5 \%$ of the undisturbed flow. This may be attributed to a speed-up of the winds as they flow around the tower structure, due to the conservation of mass, but may also indicate a slowdown on the upstream side of the tower.

\subsection{Turbulent kinetic energy}

In the wake of the tower, the turbulence is expected to increase, so a comparison similar to Sect. 3.1 was completed to identify increases in TKE due to the tower wake. TKE is defined by

$\mathrm{TKE}=\frac{1}{2}\left(\overline{u^{\prime 2}}+\overline{v^{\prime 2}}+\overline{w^{\prime 2}}\right)$,

where $u^{\prime}, v^{\prime}$, and $w^{\prime}$ are perturbations from the $20 \mathrm{~min}$ average wind speed (a typical timescale for turbulent quantities in the PBL). The TKE from the northwest sonic anemometer can be compared to that of the southeast sonic anemometer in directional bins to identify angles at which one sonic anemometer is in a wake (Fig. 7). Using $5^{\circ}$ bins of $20 \mathrm{~min}$ mean wind direction measured by the southeast sonic anemometer (red line), the wake effect on the northwest sonic anemometer is observed as a high bias in TKE between 300 and $25^{\circ}$. To identify the wake on the southeast sonic anemometer, the direction from the northwest sonic anemometer is used (blue line), and the southeast sonic anemometer measures higher TKE than the northwest between 100 and $175^{\circ}$. Interestingly, the ratio of mean wind speeds is symmetric for each boom (i.e., the ratios vary from 0.5 to 2 ), but for TKE the ratios vary from 0.75 to 2 , showing a lesser wake effect downstream of the tower for winds out of the southeast. A scatterplot of the TKE measured on the northwest versus southeast booms is shown in Fig. 8. Data points when the northwest booms in the tower wake are shown in red and lie above the one-to-one line, when the southeast booms in the wake are in blue and lie below the one-to-one line, and the unwaked values are in green, lying on the one-to-one line. A difference of up to an order of magnitude in TKE is observed in the wake of the tower.

\subsection{Correlation between sonic anemometers}

Because of the inverse effect on the wind speed ratio at the boundaries of the wake regions in Fig. 5, we use a second approach to precisely define the angular regions affected by the tower. This approach employs the coefficient of determination, $R^{2}$, between the 2 min mean wind speeds from the two

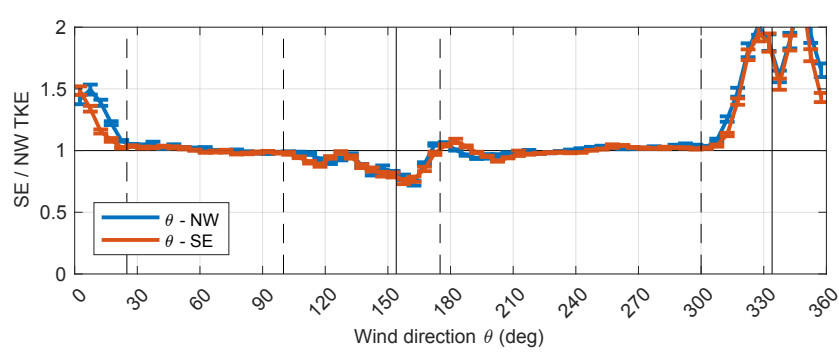

Figure 7. Ratio of 20 min turbulent kinetic energy (TKE) from the southeast versus northwest sonic anemometers at all six heights for the full 3 months of measurements during XPIA, in $5^{\circ}$ wind direction bins as determined by the northwest (blue) and southeast (red) sonic anemometers. Solid vertical lines indicate the orientations of the booms at 154 and $334^{\circ}$ from north and dashed vertical lines indicate the boundaries of the wake, defined by the TKE increase, at $100-175$ and $300-25^{\circ}$. Error bars represent 1 standard deviation of the mean.

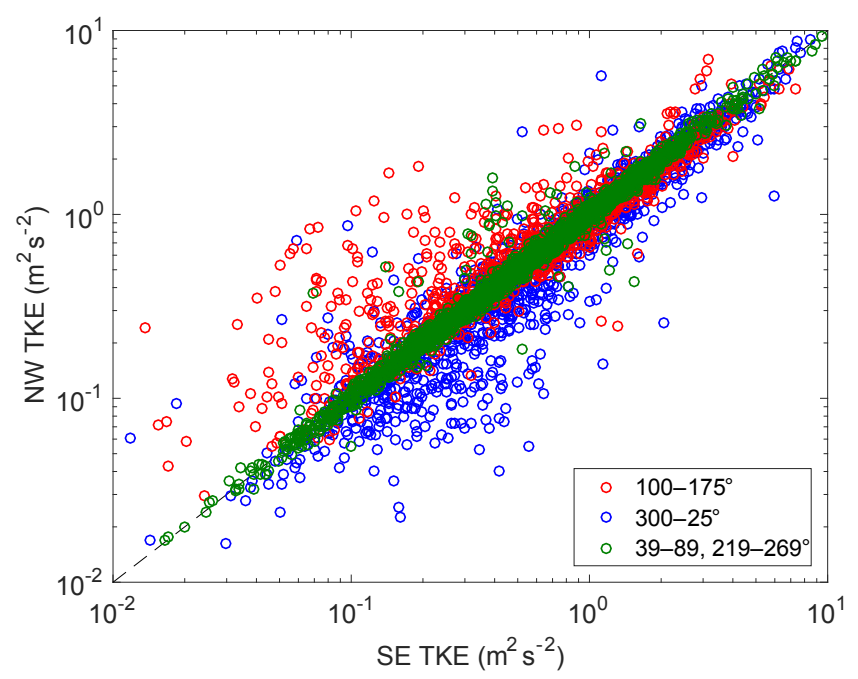

Figure 8. Twenty-minute TKE (on a logarithmic scale) from the northwest and southeast sonic anemometers at $50 \mathrm{~m}$ in three bins containing the northwest sonic anemometer's wake (100-175 red), the southeast sonic anemometer's wake (300-25 $5^{\circ}$, blue), and non-wake regions (38-89 and 219-269 ${ }^{\circ}$, green). The black dashed line is the one-to-one line.

sonic anemometers as a function of wind direction, computed in $1^{\circ}$ bins and smoothed over $3^{\circ}$ averages, shown in Fig. 9a. $R^{2}$ values are very close to 1 when neither sonic anemometer is in a wake, and the wake or speed-up regions are identified as the ranges with decreased correlation surrounding the boom direction (shown in the solid vertical black lines). The standard deviation of the binned values of $R^{2}$ between 50-100 and $200-275^{\circ}$, where no wake effects are expected, was calculated. The boundary of the wake was determined to be the direction at which the $R^{2}$ value fell below 3 standard deviations from the mean $R^{2}$ value (0.987 and 0.9976) of the non-wake regions. The four boundaries of the wakes were 

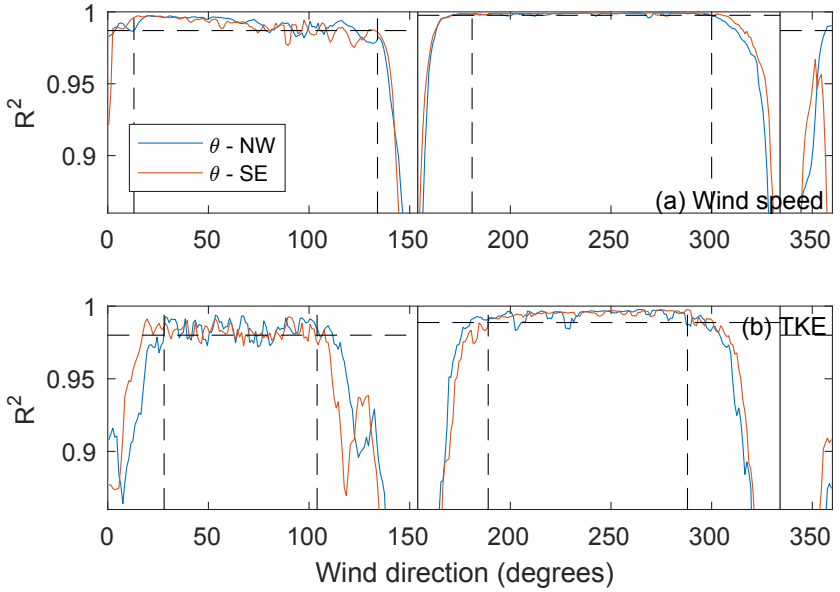

Figure 9. Coefficient of determination, $R^{2}$, of the 2 min mean wind speeds (a) and $20 \mathrm{~min}$ TKE (b) measured by the southeast and northwest sonic anemometers at all heights for the full 3 months of measurements, binned into $1^{\circ}$ wind direction intervals, and smoothed with a running mean of $3^{\circ}$. The boom orientations are shown in solid black vertical lines, and dashed vertical lines denote the wakes as determined by the limits in the horizontal dashed lines. The blue line uses the wind directions from the northwest sonic to identify the wake formed around the southeast sonic anemometer near $334^{\circ}$, and the red line uses the wind directions from the southeast sonic anemometer to identify the wake around the northwest sonic anemometer near $154^{\circ}$.

found when the limit for the adjacent region was crossed (intersection of the dashed lines in Fig. 9a). This method determined a range of winds coming from 134 to $181^{\circ}$, creating a wake around the northwest sonic, and from 300 to $13^{\circ}$ waking the southeast sonic, as shown by the dashed vertical black lines.

Using the same method applied to the TKE, and all 3 months of $20 \mathrm{~min}$ measurements at all heights, the coefficients of determination, $R^{2}$, between the two sonic anemometers were again computed for each $1^{\circ}$ wind direction bin (and smoothed over $3^{\circ}$ intervals) and shown in Fig. 9b. The large decreases in correlation are seen around the boom orientations, though the angular swaths of wake impacts are wider for TKE than for mean wind speed. The $R^{2}$ limits (3 standard deviations from the average in the ranges $50-100$ and $200-275^{\circ}$ for the adjacent boundaries: 0.9887 and 0.980 ) are found, and the wake regions are defined, shown as dashed vertical lines in Fig. 9b. These results show the northwest sonic anemometer is in the tower wake when the winds are coming from 104 to $189^{\circ}$, and the southeast sonic anemometer is in the wake when winds are coming from 288 to $28^{\circ}$. These ranges are somewhat larger than those just from the mean velocity deficit in Fig. 5, but they include a portion of the speed-up/blockage regions as well (see Table 1).

The range of directions found to be influenced by the BAO tower using $R^{2}$ of TKE in Fig. 9b is larger than those found
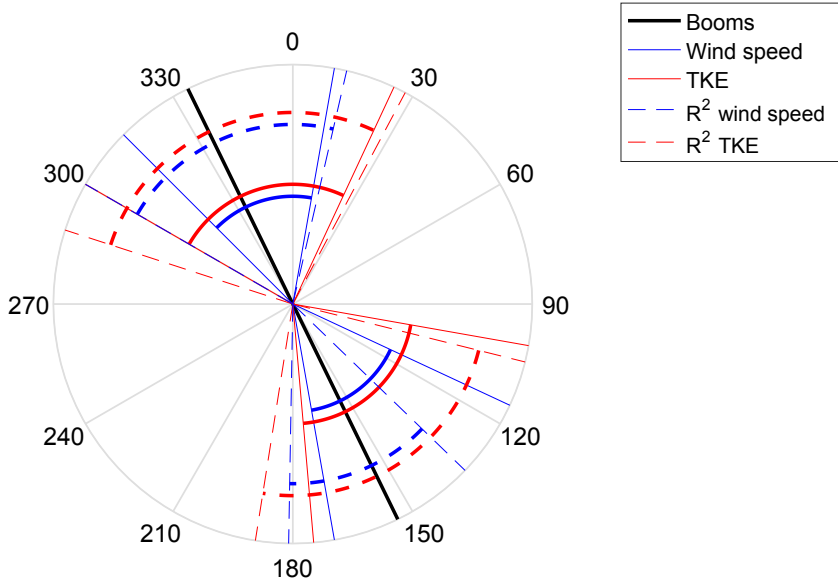

Figure 10. Wind directions from which the tower wake is apparent, as determined by the sonic anemometer comparisons of mean wind speed (blue) and TKE (red), using the ratio plots (solid) and correlation (dashed). Arcs span the ranges for each method. The orientations of the booms are also shown at 154 and $334^{\circ}$ (black solid lines).

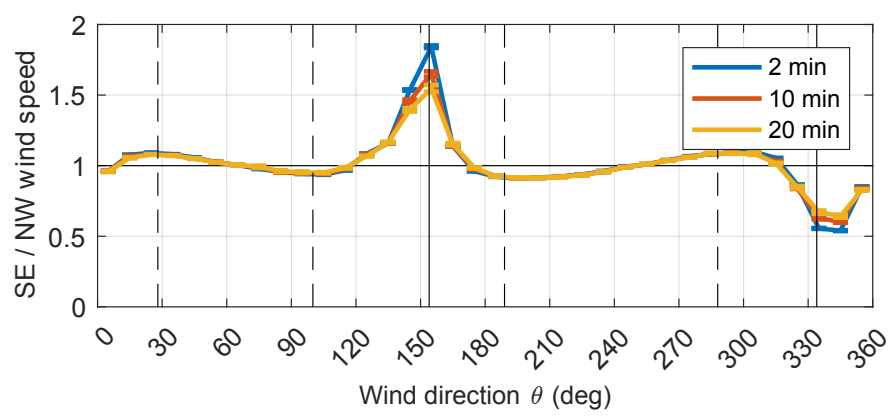

Figure 11. Ratio of southeast to northwest sonic anemometers' wind speed, calculated over $2 \mathrm{~min}$ (blue), $10 \mathrm{~min}$ (red), and $20 \mathrm{~min}$ (yellow) intervals, using data from all heights of the BAO tower. Vertical solid lines denote the boom orientation angles, and the vertical dashed lines denote the largest tower-wake boundaries in Table $1\left(100-189\right.$ and $\left.288-28^{\circ}\right)$.

for $R^{2}$ of mean wind speed in Fig. 9a. Figure 10 summarizes the results of the wake identification using the pairs of sonic anemometers, showing a compass of wind directions with the blue lines demarcating the wake boundaries as determined from the mean wind speed analysis and the red lines as the demarcation of the boundaries from the TKE analysis, both using the ratios (solid lines) and correlation (dashed lines). The angular widths of the wake regions determined by the TKE analysis are slightly wider, so sonic anemometer data being used for fluxes or second-order moments should discard this wider range of wind directions for the downwind sonic anemometer. Furthermore, the angular ranges determined by the correlation are larger than using the ratios in nearly all cases (Table 1). Users of these data could define a different threshold of correlation than the one used here in 
order to be either more strict or more lenient toward the observations impacted by the tower.

The location of the tower structure in relation to the booms causes asymmetry in the tower-wake effects. For both northwest and southeast wakes, the extent of the wake region to the east of the boom orientations, i.e., clockwise from the northwest boom, counterclockwise from the southeast boom, is larger than the impacted directions on the west side (Fig. 10 and Table 1). The mean wind speeds decrease out to 16 and $19^{\circ}$ toward the west (clockwise from the southeast boom and counterclockwise from the northwest booms, respectively), but on the east side, the impacts extend 39 and $36^{\circ}$ from southeast and northwest booms, respectively. Based on TKE, the tower impacts extend $51^{\circ}$ to the east (clockwise) from the northwest boom and $54^{\circ}$ east (counterclockwise) from the southeast boom, while, to the west, the wakes only reach 34 and $21^{\circ}$ from the northwest and southeast booms, respectively. Figure 9 also indicates the impact of the asymmetrical tower, as the correlation between mean wind speed and TKE at pairs of sonic anemometers is lower in the free-stream regions between 30 and $100^{\circ}$ (the directions for which the tower structure is upstream from the booms) than 200 and $290^{\circ}$ (the directions for which the tower structure is downstream from the booms).

\subsection{Time-averaging effects on wake magnitude}

Different applications and uses of tall tower data require different averaging intervals, so a comparison was completed to determine the effect that averaging has on the magnitude of the BAO tower wake. Flux studies are interested in high-frequency fluctuations over a 20 or $30 \mathrm{~min}$ interval, while wind energy studies tend to use shorter, often $10 \mathrm{~min}$ (Brower and Bernadett, 2012), averages for resource assessment and model comparisons. To identify the effect that longer averages has on the tower wake, Fig. 11 compares the mean wind speed ratio between southeast and northwest sonic anemometers, calculated over 2, 10, and 20 min averaging intervals. The $2 \mathrm{~min}$ average creates the largest wake impact, with decreasing magnitude with longer averages in wind speed. This occurs because, over longer averages, it is increasingly likely that only a portion of the interval is in the tower wake and thus has a smaller impact on the overall ratio. Therefore, short timescale analyses will see larger impacts from the wake. The angular extent of the wake does not, however, change with the averaging time. It is only the magnitude, not width, of the peak or deficit in ratio that changes. The magnitude of the inverse effect (downstream speed-up or upstream slowdown) also does not change with averaging time, indicating that this is a stationary feature around the tower.
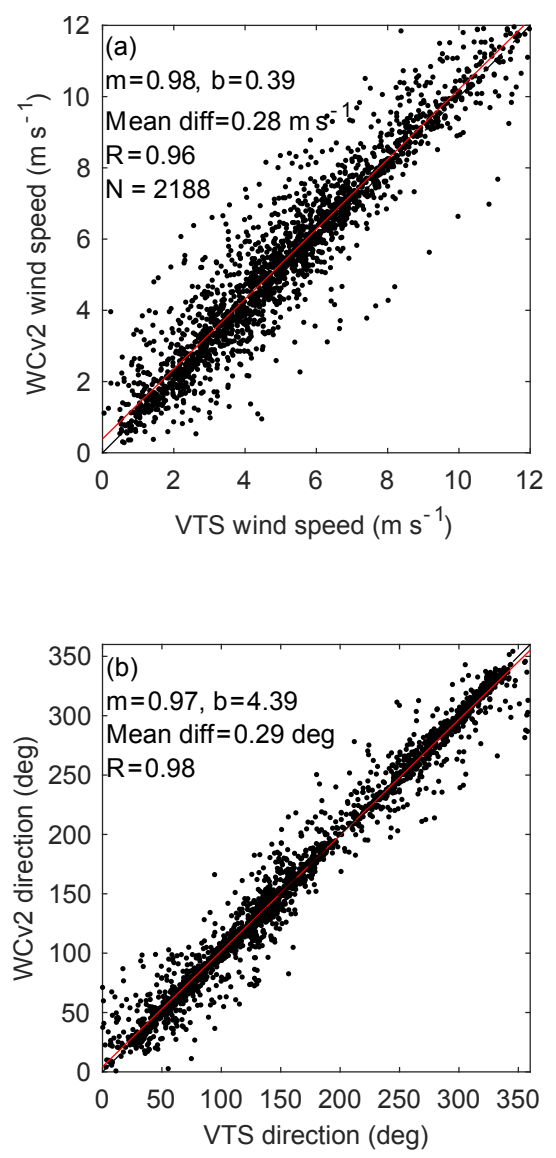

Figure 12. (a) Scatterplot of $25 \mathrm{~s}$ wind speeds from the WINDCUBE $^{\circledR}$ V2 (WCv2) and accumulations of wind speed from the virtual tower stares (VTS) over the lidar super site, using data from 9 days of the three $200 \mathrm{~S}$ lidars performing coordinated stares over the supersite location at heights of 100 to $200 \mathrm{~m}$ above ground with $20 \mathrm{~m}$ increments (number of points, $N=2188$ ). The black dashed line is the one-to-one line, and the red line is the line of best fit, with slope, $m$, and intercept, $b$, as noted. The mean difference between measurements, and correlation coefficient, $R$, are also shown. (b) Same as in panel (a), but for wind direction.

\section{Wake identification: sonic anemometer versus lidar observations}

With several profiling and scanning lidars in operation during XPIA, these additional independent instruments are leveraged to identify the boundaries of the BAO tower wake. Included were the WCv2 profiling lidar and the three Leosphere 200S scanning lidars that performed synchronized virtual tower scans for 3-D wind retrievals adjacent to the BAO tower (discussed in Sect. 4.2). These independent measurements are employed here to confirm the angular extent of the BAO tower-wake boundaries and their influence on the sonic anemometers.

In order to determine whether the two lidar measurement techniques used in this analysis are equivalent (and, thus, that 
Table 1. Angular swaths (in degrees) determined by the mean wind speed and turbulent kinetic energy (TKE) for the wake around the northwest and southeast sonic anemometers. Columns indicate swath counterclockwise (CCW) and clockwise (CW) from boom of interest.

\begin{tabular}{lrrr|rrr}
\hline & $\begin{array}{r}\text { CCW from } \\
\text { SE boom }\end{array}$ & $\begin{array}{r}\text { CW from } \\
\text { SE boom }\end{array}$ & $\begin{array}{r}\text { Angular } \\
\text { range }\end{array}$ & $\begin{array}{r}\text { CCW from } \\
\text { NW boom }\end{array}$ & $\begin{array}{r}\text { CW from } \\
\text { NW boom }\end{array}$ & $\begin{array}{r}\text { Angular } \\
\text { range }\end{array}$ \\
\hline Wind speed & 39 & 16 & $115-170$ & 19 & 36 & $315-10$ \\
TKE & 54 & 21 & $100-175$ & 34 & 51 & $300-25$ \\
$R^{2}$ wind speed & 20 & 27 & $134-181$ & 34 & 39 & $300-13$ \\
$R^{2}$ TKE & 50 & 35 & $104-189$ & 46 & 54 & $288-28$ \\
\hline
\end{tabular}

any differences between the lidars and the sonic anemometers are due to the sonic anemometers themselves), VTS measurements were made over the lidar supersite and are compared to the WCv2 measurements (Fig. 12). The VTS data compared with the WCv2 were collected continuously for a period of 9 days with the three $200 \mathrm{~S}$ lidars performing $25 \mathrm{~s}$ coordinated stares over the supersite location at heights of 100 to $200 \mathrm{~m}$ a.g.l. with $20 \mathrm{~m}$ increments. These LOS measurements from the three 200S lidars over these $25 \mathrm{~s}$ were least squares fitted to obtain the wind speed and direction over the $25 \mathrm{~s}$ measurement period. In order to perform a comparison with the WCv2 over similar time averages, the $1 \mathrm{~Hz}$ WCv2 wind measurements (obtained by least squares fitting beams within a moving five-beam window) were averaged over $25 \mathrm{~s}$ to match the time resolution of the VTS stares. The comparison of the VTS and WCv2 measurements thus performed is shown in Fig. 12. The wind measurements from the WCV2 and VTS agree well with slopes close to 1, correlation coefficients of 0.96 (0.98), and mean differences of $0.28 \mathrm{~m} \mathrm{~s}^{-1}\left(0.29^{\circ}\right)$ for wind speed (wind direction). The differences in wind measurements may be due to the different measurement volumes being averaged; the volume of the VTS can be approximated as a circle of diameter $60 \mathrm{~m}$ and vertical extent of $15 \mathrm{~m}\left(\sim 30625 \mathrm{~m}^{3}\right)$, and the volume of the WCv2 is a conical frustum with volumes of $\sim 40000$ to $400000 \mathrm{~m}^{3}$. These lidar measurements are used here as an independent measurement to support the results of the sonic anemometer comparisons and to further identify the wake effects of the tower on the individual sonic anemometers. The magnitude of the wake effect as estimated from the two lidar measurements was found to be higher than the instrument error and measurement differences between the VTS and $\mathrm{WCV} 2$.

\subsection{WCv2 profiling lidar}

Using the WCv2 situated $130 \mathrm{~m}$ south of the BAO tower, further comparisons of the 2 min mean wind speeds were calculated to identify times when the sonic anemometers at each boom of the tower observed substantially different winds than those observed by the lidar, which measured undisturbed, free-stream winds. The mean wind speed ratio of the WCv2 lidar versus each sonic anemometer is shown in the blue lines in Fig. 13, with a prominent velocity deficit measured around the boom orientation direction for each sonic anemometer. Similar to the comparison between sonic anemometers, the wind speed deficit measured by the sonic anemometer in the wake region is up to $40 \%$ of the freestream wind speed, measured here by the WCv2 as well. The speed-up adjacent to the wake regions is not seen in the wind speed ratio between the WCv2 and the sonic anemometers, as the ratio never exceeds 1 . However, the wind speed ratio dips below 1 for wind directions surrounding the upstream boom (280-30 for the northwest sonic anemometers and 90-210 for the southeast), indicating a slight slowdown of velocities or blockage on the upstream side of the tower.

In this comparison, it is also possible to see that neither wake is symmetric about the booms. At the northwest boom, the largest wake effects occur when the winds are coming from the angles counterclockwise from the boom orientation, i.e., with a greater easterly component, which flows through the tower. The southeast sonic anemometers experience their slowest speeds at angles adjacent to the northwest boom orientation but also see a broader impact to the east (clockwise) of the boom orientation, where the tower structure is located.

\subsection{Triple-doppler virtual tower stares}

Using the 3 days of VTS at the BAO tower to identify the tower wake, the red and yellow lines in Fig. 13 show the comparison of the high-resolution $2 \mathrm{~s}$ and 2 min mean wind speeds, respectively, from the virtual tower with the corresponding mean wind speeds from the sonic anemometers on the northwest (top panel) and southeast (bottom panel) booms of the BAO tower. Here, the tower wake is clearly identified in the wind speed deficit surrounding the booms. At the northwest boom, the deficit peaks at $55 \%$ of the lidar wind speed in both $2 \mathrm{~s}$ and 2 min mean speeds. This peak is centered at a counterclockwise orientation from the boom orientation, which is consistent with the wake regions determined from the sonic anemometer comparisons. The difference in averaging times appears in the speed-up region, where the 2 min mean wind speeds increase less than the $2 \mathrm{~s}$ ratios, which have an $8 \%$ increase on the flanks of the wakedeficit regions. The 2 min ratios match those seen in Fig. 5. For both averaging times, the wind speed ratios eventually level out to 1 , but the $2 \mathrm{~s}$ observations have a larger range of angles where the ratio lies above 1 . Both averaging times 


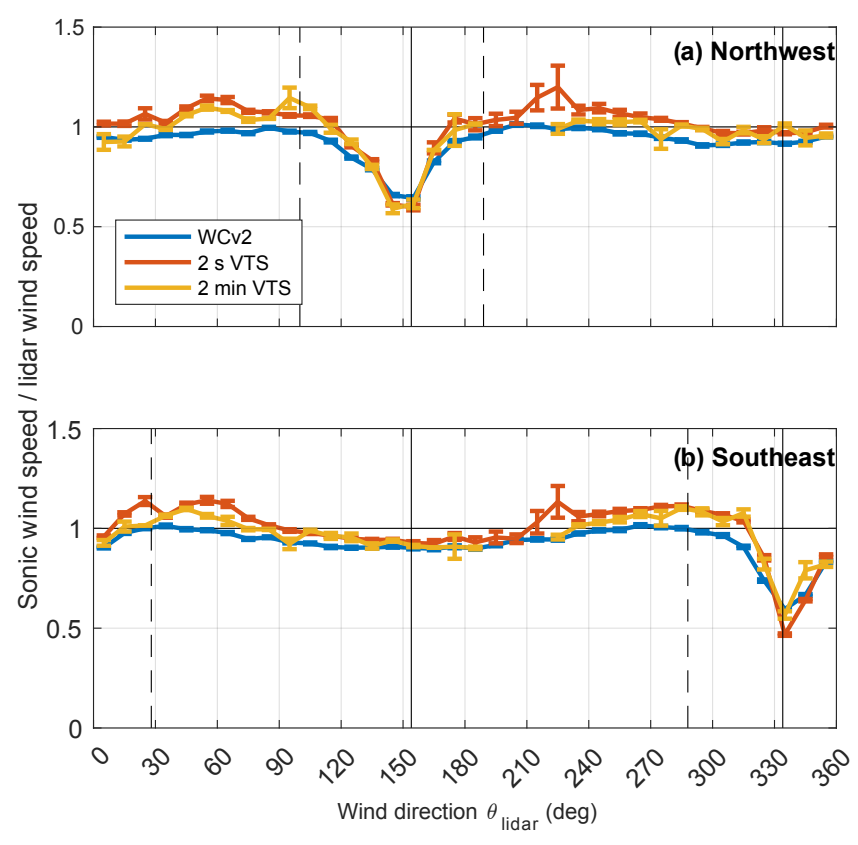

Figure 13. Ratio of mean wind speed from the northwest (a) and southeast (b) sonic anemometers versus the 2 min WINDCUBE ${ }^{\circledR}$ V2 (WCv2) profiling lidar (blue) and $2 \mathrm{~s}$ (red) and 2 min (yellow) virtual tower stares (VTS) at the BAO tower, for all heights $(50 \mathrm{~m}$ intervals from 50 to $150 \mathrm{~m}$ ), in $10^{\circ}$ bins as determined by the respective lidar's wind direction. WCv2 comparisons cover the entire period from 12 March to 31 May 2015, and VTS comparisons at the BAO tower span the 3-day period from 21 to 24 March 2015. Vertical dashed lines denote the largest tower-wake boundaries in Table 1 (100-189 and 288-28 $)$.

experience a $5 \%$ speed-up outside of the wake region, but, as with the northwest sonic anemometers, the $2 \mathrm{~s}$ wind speed ratios remain higher over a larger range of angles. Unlike the northwest side, the VTS wind speed ratios at the southeast sonic anemometers dip below 1 for directions between 120 and $210^{\circ}$. This difference between northwest and southeast upstream behavior is not, however, seen in the WCv2, and is not visible in the comparisons of sonic anemometer measurements since both sonics would be experiencing decreased wind speeds, and the ratio is dominated by the downstream deficit.

In the range from 30 to $120^{\circ}$ on Fig. $13 \mathrm{a}$ and 10 to 80 on Fig. 13b, the wind speed ratio remains above 1, resembling an extended speed-up region. This suggests that winds coming from the north to east are speeding up as they flow around the tower, affecting the southeast booms, and from the east and southeast, speeding up as they approach the northwest boom. This is most likely due to the triangular structure of the tower pointing to the northeast, causing winds to flow around the tower before reaching the sonic anemometers. The WCv2 does not see this decrease in wind speeds (increase in wind speed ratio) but, since it is $130 \mathrm{~m}$ away from the BAO tower, it is expected to be less sensitive to the smaller perturbations

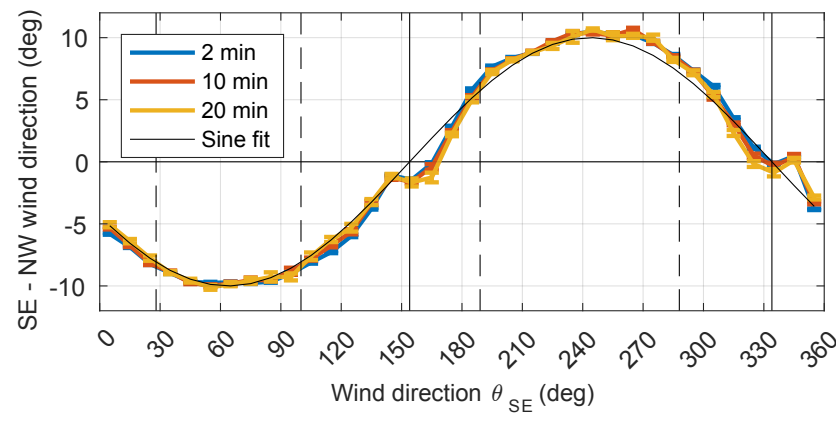

Figure 14. Difference in wind direction between the sonic anemometers on the two booms (southeast minus northwest), calculated over $2 \mathrm{~min}$ (blue), $10 \mathrm{~min}$ (red) and $20 \mathrm{~min}$ (yellow) intervals, using data from all six heights of the BAO tower, in $10^{\circ}$ bins as determined by the southeast sonic anemometers' wind directions. The thin black line is the approximate sine-function fit, $\Delta \theta=10 \sin (\theta-154)$. Vertical solid lines denote the boom orientation angles, and the vertical dashed lines denote the largest towerwake boundaries in Table 1 (100-189 and 288-28 $8^{\circ}$.

introduced due to the tower compared to the VTS. Lack of data from the VTS prevent this instrument alone from being used to identify the exact extent of the wakes, but its results support those of the extensive sonic anemometer and profiling lidar comparisons.

\section{Flow deflection around tower}

While the tower sonic anemometer wind speeds are affected over a range of angles around each boom, the wind direction may also vary in a manner independent from the wind speed deficit and TKE increase. The example time series from Fig. 4 shows a consistent difference in wind direction, where the northwest sonic anemometer measures slightly smaller angles (more counterclockwise directions) around $280^{\circ}$, and the southeast sonic anemometer measures slightly smaller angles around $50^{\circ}$. To further examine this, Fig. 14 plots the difference in wind direction measured by the sonic anemometers on opposite sides of the tower as the wind direction changes. The difference in angle follows a sinusoidal variation, approximately following the thin black line of $\Delta \theta=10 \sin \left(\theta_{\mathrm{SE}}-154\right)$. Differences up to $10^{\circ}$ are seen in ranges around 30 to 90 and 220 to $280^{\circ}$, which are in the free-stream regions, not near the orientations of the booms. In fact, only when the winds are blowing directly along (or $10^{\circ}$ off from) the boom orientation - when one boom is in the wake - are the observed wind directions the same. Contrary to the differences seen in mean wind speed and TKE with averaging times, there is very little impact on direction difference when averaging for longer periods (different colored lines). These results show that the deflection around the tower is a consistent, large-scale feature that is not reduced by averaging. 


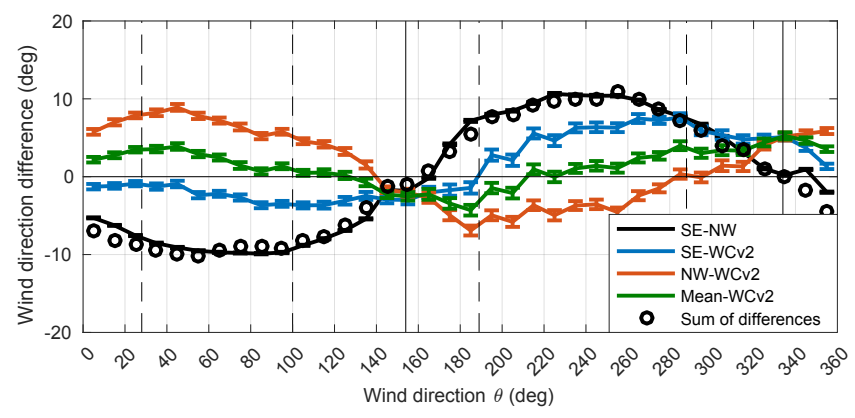

Figure 15. Difference in 2 min mean wind direction between the sonic anemometers on the two booms (southeast minus northwest: solid black; mean of southeast and northwest: green) in $10^{\circ}$ bins as determined by the southeast sonic anemometers' wind directions and the WINDCUBE ${ }^{\circledR}$ V2 profiling lidar at 50, 100, and $150 \mathrm{~m}$ (southeast sonic anemometers minus WCv2: blue; northwest sonic anemometers minus $\mathrm{WCv} 2$ : red), in $10^{\circ}$ bins as determined by the WCv2 wind directions. Black circles are the sum of the differences between the sonic anemometers and the WCv2. Vertical solid black line denotes the orientations of the booms, and vertical dashed lines denote the largest tower-wake boundaries in Table 1 (100-189 and $\left.288-28^{\circ}\right)$.

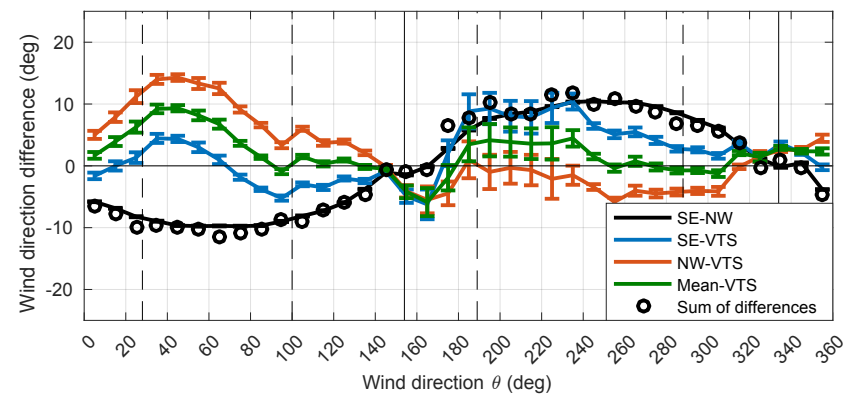

Figure 16. Same as Fig. 15, but showing the difference in wind direction between the $2 \mathrm{~s}$ sonic anemometer and virtual tower stare (VTS) measurements.

Using the independent measurements of wind direction from the WCv2 and scanning lidars' virtual tower, the direction difference observed by each sonic anemometer individually is also quantified in Figs. 15 and 16. The overall behavior of the direction difference between the sonic anemometers (shown in black) and each lidar system is similar, with more variation in the VTS due to the shorter time span of the comparison and fewer points in each direction bin. There is agreement in behavior between the two lidar systems and the sonic anemometers, with asymmetrical behavior around the tower, as the northwest and southeast sonic anemometers do not deviate from the lidars' measurements in the same fashion. From 0 to $150^{\circ}$, the directional difference between sonic anemometers is almost completely due to the northwest sonic, and the difference between the southeast sonic anemometer and the lidars is small, in the opposite direction. Neither sonic anemometer is in a wake in this region, so any deflection around the tower would be expected to be symmetrical. The direction of the biases is symmetrical, but not the amplitude. However, on the opposite side of the tower, when winds are coming from 150 to 360 , both sonic anemometers show deviations in direction, though not in a completely symmetrical fashion. The sum of the differences (black circles) between each sonic and the lidar measurements follows the behavior of the differences between sonic anemometers (black lines), showing that both booms experience deflected flow that contributes to the total difference. Since the deflections are generally in the opposite direction for the two sonic anemometers, averaging the directions of the two sonic anemometers before comparing to the lidar decreases the wind direction difference (green lines) and is a preferred use of wind direction data from the sonic anemometers, since there is always a deflection measured around the tower. Averaging of wind speeds could also be done, though the differences outside of the wake are far smaller so it is less necessary. The difference from the average wind direction between sonics (green lines in Figs. 15 and 16) is positive at almost all wind direction angles, i.e., sonics measure winds rotated clockwise from the lidars.

Figure 17 summarizes the behavior of the flow around the tower, as shown by the vectors of sonic anemometer and lidar (VTS) winds, as well as the difference, overlaid on the tower schematic. The data are binned in $10^{\circ}$ intervals of the $2 \mathrm{~s}$ VTS winds (black), and the corresponding sonic anemometer measurements, shown in red vectors, are overlaid (the same figure was made using the WCv2 winds over the full 3 months of XPIA, with consistent results). This figure shows the deviations from the expected wind direction from the VTS were the tower to have no impact. It is clear, however, that there are significant directional differences, in addition to the wake impact on wind speed apparent in the length of the black and red vectors. The general behavior is shown in the green arced arrows. The flow out of the east has a smaller effect on the southeast sonic anemometer's measurements, though generally follows the flow deflected toward the south, while the northwest sonic anemometer experiences flow that has been deflected significantly around the tower, toward the north. For winds from the west, both sonic anemometers experience flow that has been deflected by the tower, in opposing directions away from the tower: toward the north on the northwest sonic anemometers and toward the south on the southeast sonic anemometers. The perturbation vectors also show that the magnitude of the deflection is greater for winds from the east for the northwest sonic anemometers and slightly higher for winds from the west for the southeast sonic anemometers. The reason for the difference in deflection is not understood, as the behavior across the axis of symmetry is expected to be equal. 


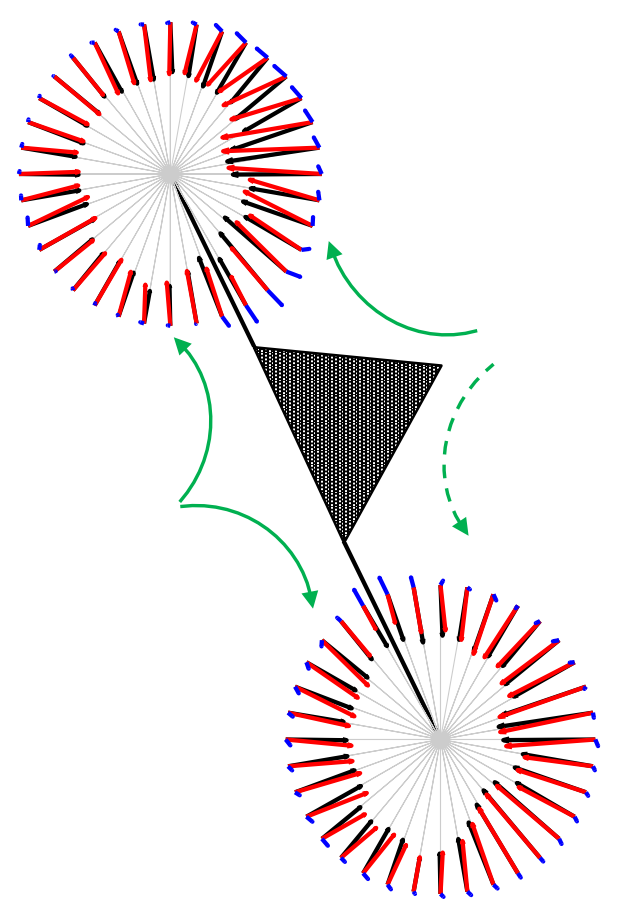

Figure 17. The vector representations of the average winds measured by the sonic anemometers at all heights (red) and the $2 \mathrm{~s}$ VTS (black), on the tower layout, with the vector of the perturbation in blue. Green curved arrows summarize the general trends around the sides of the tower with consistent behavior, with a dashed line indicating less consistent behavior in that quadrant.

\section{Temporal extent of wake impacts}

Once the directions of tower influences has been determined, the question arises as to what fraction of data points are in a wake in a temporal averaging interval, and how it will substantially alter the mean observation away from the freestream value. This section aims to determine the relation between the fraction of an averaging time interval that a sonic anemometer is in a wake and the error of the 2 min mean wind speed and 20 min TKE. It is hypothesized that the turbulent quantities will be more affected than the mean by a small percentage of measurements in a wake in each interval. For example, if $20 \%$ of the time-averaging interval from the sonic anemometer is in a wake, then the true average speed (as measured by the upstream sonic anemometer or lidar) may be captured sufficiently accurately, and the interval may not need to be discarded. However, removing $20 \%$ of the observations from a $20 \mathrm{~min}$ value of TKE will likely have a larger impact, and the whole interval may need to be discarded.

To determine the effect that an increasing percentage of observations in a wake has on each value of mean wind speed and TKE, the data points from the sonic anemometers in the tower wakes were removed, and the 2 min mean and $20 \mathrm{~min}$ TKE values were calculated using the remaining data. To reduce the effect of very high frequency direction fluctuations in the $20 \mathrm{~Hz}$ sonic anemometer observations that may have an instantaneous value of a wake direction but whose trajectory would not have come through the tower, the $1 \mathrm{~s}$ average wind speed and direction were calculated, and the winds in the range of wake directions (100-189 and 288$28^{\circ}$ ) were then removed. Over each 2 or 20 min averaging interval, the percentage of $1 \mathrm{~s}$ observations in a wake was saved, and the mean absolute error (MAE) between the two sonic anemometers was determined for each quantity, binned by the percentage of data in a wake in each interval. The values that go into the MAE calculation are chosen based on the sonic anemometer with the highest percentage of values in a wake in each particular 2 or $20 \mathrm{~min}$ interval (e.g., for one $2 \mathrm{~min}$ interval, if $10 \%$ of the $1 \mathrm{~s}$ averages are in the wake at the southeast sonic anemometer and $4 \%$ of the northwest sonic anemometer is in the wake, the pair at that time step goes into the $10 \%$ bin). Figure 18 shows the MAE for the two quantities versus the percentage of $1 \mathrm{~s}$ observations that are in a wake in each interval; the top panel (a) shows the MAE between the two sonic anemometers for mean wind speed while the bottom panel (b) is the same for TKE. When neither instrument has any $1 \mathrm{~s}$ observations in a wake, the MAE between the sonic anemometers is around $5 \%$ for mean wind speed and $8 \%$ for TKE. The MAE for mean wind speed is lowest for time intervals containing small percentages of data points in a wake, then sharply increases from 5 to $8 \%$ in MAE for time intervals with $5 \%$ of the observations in a wake. As the removal of data in the tower wakes increases, the MAE remains nearly constant, remaining below $13 \%$ MAE until $90 \%$ of the data points in the 2 min intervals are in a wake. This is equivalent to $1 \mathrm{~min}$ and $48 \mathrm{~s}$ of observations in a wake being removed from the 2 min interval over which the mean wind speed is calculated. For the strictest data quality control all $2 \mathrm{~min}$ intervals should be removed if they contain any $1 \mathrm{~s}$ observation values in one of the tower wakes (approximately $55 \%$ of the time, shown in the histogram in Fig. 18a), but for less stringent quality control, all intervals with less than $90 \%$ of observations in a wake could be kept, since the disagreement between sonics is still below $15 \%$. Above $90 \%$, however, the error between sonics greatly increases, and the values in the wakes dominate the mean wind speed. Nearly half of the 2 min intervals in the entire 3-month XPIA dataset never experience any wake effects (the $0 \%$ bin in the histogram), while $30 \%$ of the $2 \mathrm{~min}$ intervals experience wake effects the entire time. After a similar increase in MAE in the bin for $5 \%$ of observations in the wakes, the error in TKE remains less than that of the mean speed until it begins a steady increase. This results in $13 \%$ disagreement between sonics when $70 \%$ of the $1 \mathrm{~s}$ observations are in a wake. Similar to the MAE in wind speed, above $90 \%$ in a wake, there is a jump in MAE in TKE. Calculating the root mean squared error (RMSE) in wind speed and TKE between sonic anemometers produces similar behavior: after an immediate increase from 0 to $5 \% 1 \mathrm{~s}$ observations 

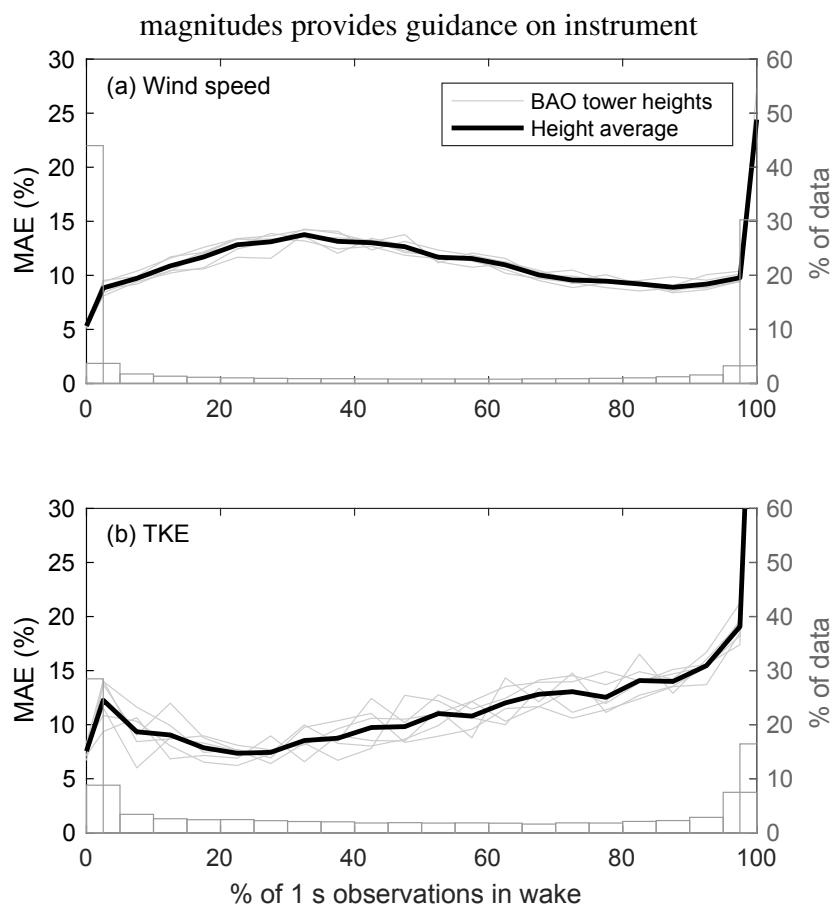

Figure 18. The mean absolute error (in percent) for the 2 min mean wind speed (a) and 20 min TKE (b) versus percentage of $1 \mathrm{~s}$ averages of the $20 \mathrm{~Hz}$ sonic anemometer observations which are in the tower wake and have been removed from the 2 or 20 min intervals. All six BAO tower measurement heights are shown in gray, with the mean over all heights in black. The distribution of all observations that contribute to each bin (averaged over all heights) is shown in bars, with labels on the right axis of both plots for the respective time intervals.

in the wakes, the RMSE levels off and then steeply increases at $90 \%$, but, since the RMSE is more sensitive to outliers, the results are noisier. We note that about $30 \%$ of the $20 \mathrm{~min}$ intervals never experience a wake (the $0 \%$ bin in the figure), but only $18 \%$ of the XPIA dataset is completely in a wake (the $100 \%$ bin in the figure). Therefore, removing all values either completely or partially contained in the tower wake still leaves a substantial portion of clean data, which have low error between sonic anemometer observations.

\section{Conclusions}

When wind speeds from the sonic anemometers mounted on opposing sides of the $300 \mathrm{~m} \mathrm{BAO}$ tower are compared to each other (Fig. 5), the effects of the tower wakes on the downstream instrumentation and speed-up around the tower are quantified. Wind speed deficits up to $50 \%$ are observed by the sonic anemometer in the wake of the BAO tower between 115 and 170 , and 315 and $10^{\circ}$ from north, with significant decreases in correlation from 134 to 181 and 300 to $13^{\circ}$. Furthermore, just outside the boundaries of the wake re- gions that experience decreased wind speeds, the downwind sonic anemometers experience a $5 \%$ increase in wind speed over the upstream sonic anemometers, which tapers off as the wind direction rotates away from approximately downwind to a more perpendicular direction. Comparisons of turbulent kinetic energy measured by opposing sonic anemometers showed a wider range of angles impacted by the BAO tower structure - including portions of the region of speed-up - from 100 to 175 and 300 to $25^{\circ}$ from north, with significant decreases in correlation from 104 to 189 and 288 to $2^{\circ}$. The asymmetry of tower-wake effects around the booms is due to the placement of the booms on the southwest face of the triangular tower (Fig. 1), which causes flow from the southwest to interact with the tower differently than winds from the northeast. These wake regions were confirmed by observations of the mean wind speed from WINDCUBE ${ }^{\circledR}$ V2 profiling lidar and virtual tower stares from triple-Doppler retrievals from scanning lidars.

Following a similar comparison method to that of wind speed, deflection of the winds was observed by differences in wind direction measured between opposing sonic anemometers and the lidar systems. Bin-averaged wind direction differences up to $10^{\circ}$ were observed between sonic anemometers, and the independent measurements from the lidars showed those contributions to come from both sonic anemometers. The direction differences between the sonic anemometers and the lidars revealed behavior explained by flow deflected around the tower, as shown in Fig. 17. Even at a distance of 3-4 $\mathrm{m}$ from the tower, the flow direction is still visibly distorted by the tower, requiring careful use of these measurements. It is recommended that, when two sonic anemometers are present, the wind direction be averaged for all direction values but the wind speeds be averaged, excluding any individual sonic anemometer measurements in a tower wake. The impact of an increasing percentage of data in a wake that must be removed from the 2 min mean wind speed and TKE was shown to vary between these two quantities, so users of the sonic anemometer data must determine the threshold of allowed periods based on the application. It is recommended, considering the availability of wake-free periods during XPIA, that strict quality control is performed to guarantee the most accurate observations, free from towerwake effects. These errors must be considered when using these observations to validate other measurement techniques.

This study shows significant effects on wind speed, turbulence, and wind direction caused by the tower structure on sonic anemometer measurements. Future analysis of temperature and humidity data from tall towers may also uncover tower-wake impacts on thermodynamic quantities. For the XPIA field campaign, this tower-wake study will help identify ideal directions and time periods best suited for modeling case studies, as well as allowing more precise determination of the accuracy of profiling and scanning lidar and radar wind profiles. More generally, this study highlights that collection of high-accuracy anemometer data from tall towers requires 
a careful analysis of wake and flow distortion effects. Future use of these and other tall-tower sonic anemometer data will require careful removal of the measurements in a tower wake, using the correct range of wind directions, and appropriate thresholding of intervals with missing data due to wakes.

\section{Data availability}

All data are publicly accessible at the DOE Atmosphere to Electrons Data Archive and Portal, found at https://a2e. energy.gov/projects/xpia.

Author contributions. Katherine McCaffrey completed the primary analysis with the aid of Paul Quelet, Aditya Choukulkar and James M. Wilczak. Daniel E. Wolfe contributed his extensive use and experience with the BAO. Alan Brewer provided the lidar data. Steven Oncley provided the sonic anemometer data through the Characterizing the Atmospheric Boundary Layer (CABL) program. Julie K. Lundquist oversaw the XPIA field campaign and advised Paul Quelet. Katherine McCaffrey prepared the manuscript with contributions from all co-authors.

Competing interests. The authors declare that they have no conflict of interest.

Acknowledgements. Funding for this study was provided by the Atmospheres to Electrons (A2e) program of the US Department of Energy, Office of Energy Efficiency and Renewable Energy, Wind and Water Power Technologies Office, NOAA's Earth System Research Laboratory, and the Characterizing the Atmospheric Boundary Layer (CABL) program of the National Center for Atmospheric Research and the University of Colorado. Funding for Katherine McCaffrey was provided by the NRC RAP Postdoctoral Research Fellowship.

Edited by: L. Bianco

Reviewed by: T. Price and three anonymous referees

\section{References}

Brower, M. and Bernadett, D. W.: Wind resource assessment: a practical guide to developing a wind project, John Wiley \& Sons, p. $152,2012$.

Brown, S. S., Thornton, J. A., Keene, W. C., Pszenny, A. A., Sive, B. C., Dubé, W. P., Wagner, N. L., Young, C. J., Riedel, T. P., Roberts, J. M., VandenBoer, T. C., Bahreini, R., Öztürk, F., Middlebrook, A. M., Kim, S., Hübler, G., and Wolfe, D. E.: Nitrogen, Aerosol Composition, and Halogens on a Tall Tower (NACHTT): Overview of a wintertime air chemistry field study in the front range urban corridor of Colorado, J. Geophys. Res.-Atmos., 118, 8067-8085, 2013.
Calhoun, R., Heap, R., Princevac, M., Newsom, R., Fernando, H., and Ligon, D.: Virtual towers using coherent Doppler lidar during the Joint Urban 2003 dispersion experiment, J. Appl. Meteorol. Climatol., 45, 1116-1126, 2006.

Cermak, J. and Horn, J.: Tower shadow effect, J. Geophys. Res., 73, 1869-1876, 1968.

Dabberdt, W. F.: Tower-induced errors in wind profile measurements, J. Appl. Meteorol., 7, 359-366, 1968.

Fabre, S., Stickland, M., Scanlon, T., Oldroyd, A., Kindler, D., and Quail, F.: Measurement and simulation of the flow field around the FINO 3 triangular lattice meteorological mast, J. Wind Eng. Ind. Aerod., 130, 99-107, 2014.

Hall, F. F.: The Boulder Atmospheric Observatory and its meteorological research tower, Optics News, 3, 14-18, 1976.

IEA, I. E. A.: Recommended Practices for Wind Turbine Testing. Part 11: Wind speed measurements and use of cup anemometry, Tech. rep., 1999.

Kaimal, J. and Gaynor, J.: The Boulder Atmospheric Observatory, J. Clim. Appl. Meteorol., 22, 863-880, 1983.

Kaimal, J., Eberhard, W., Moninger, W., Gaynor, J., and Troxel, S.: Project CONDORS: Convective diffusion observed by remote sensors, Final Report National Oceanic and Atmospheric Administration, Boulder, CO, Wave Propagation Lab, 1986.

Kelley, C. L. and Ennis, B. L.: SWiFT site atmospheric characterization., Tech. rep., Sandia National Laboratories (SNL-NM), Albuquerque, NM, USA, 2016.

Lira, A., Rosas, P., Araújo, A., and Castro, N.: Uncertainties in the estimate of wind energy production, Tech. rep., Grupo de Estudos do Setor Elètrico do Instituto de Economia da Universidade Federal do Rio de Janeiro, 2016.

Lundquist, J. K., Wliczak, J. M., Ashton, R., Bianco, L., Brewer, W. A., Choukulkar, A., Clifton, A. J., Debnath, M., Delgado, R., Friedrich, K., Gunter, S., Hamidi, A., Iungo, G. V., Kaushik, A., Kosovik, B., Langan, P., Lass, A., Lavin, E., Lee, J. C.-Y., Newsom, R. K., Noone, D. C., Oncley, S. P., Quelet, P. T., Sandberg, S. P., Schroeder, J. L., Shaw, W. J., Sparling, L., St. Martin, C., St. Pe, A., Strobach, E., Tay, K., Vanderwende, B. J., Weickmann, A., Wolfe, D., and Worsnop, R.: Assessing state-of-the-art capabilities for probing the atmospheric boundary layer: the XPIA field campaign, B. Am. Meteor. Soc., doi:10.1175/BAMS-D-1500151.1, 2016a.

Lundquist, J. K., Wliczak, J. M., Ashton, R., Bianco, L., Brewer, W. A., Choukulkar, A., Clifton, A. J., Debnath, M., Delgado, R., Friedrich, K., Gunter, S., Hamidi, A., Iungo, G. V., Kaushik, A., Kosovik, B., Langan, P., Lass, A., Lavin, E., Lee, J. C.-Y., Newsom, R. K., Noone, D. C., Oncley, S. P., Quelet, P. T., Sandberg, S. P., Schroeder, J. L., Shaw, W. J., Sparling, L., St. Martin, C., St. Pe, A., Strobach, E., Tay, K., Vanderwende, B. J., Weickmann, A., Wolfe, D., and Worsnop, R.: Assessing state-of-the-art capabilities for probing the atmospheric boundary layer: the XPIA field campaign, Tech. rep., National Renewable Energy Laboratory, Golden, CO, USA, 2016 b.

Orlando, S., Bale, A., and Johnson, D. A.: Experimental study of the effect of tower shadow on anemometer readings, J. Wind Eng. Ind. Aerod., 99, 1-6, 2011.

Peña, A., Floors, R., Sathe, A., Gryning, S.-E., Wagner, R., Courtney, M. S., Larsén, X. G., Hahmann, A. N., and Hasager, C. B.: Ten years of boundary-layer and wind-power meteorology at Høvsøre, Denmark, Bound.-Lay. Meteorol., 158, 1-26, 2016. 
Stone, R., Augustine, J., Dutton, E., O’Neill, N., and Saha, A.: Empirical determinations of the longwave and shortwave radiative forcing efficiencies of wildfire smoke, J. Geophys. Res.-Atmos., 116, doi:10.1029/2010JD015471, 2011. 